presentation of the departmental estimates, annual reports and statistics, and comparisons must therefore be selective. One or two points can perhaps be established without dependence on statistics. In terms of administrative structure, for example, we in Scotland have since 1948 avoided segregating the teaching hospitals in an organisation of their own; similarly health centres have not been segregated as a local authority function; and more recently, since 1974, we have avoided segregating the family practitioner services in "vestigial executive councils." Can we perhaps claim these differences as reflecting a more integrated approach ?

Despite the difficulty of making statistical comparisons between England and Scotland, let us examine a few figures taken from the published health statistics which show the breakdown of total health expenditure for 1972-3-that is, before reorganisation (see table).

Health service expenditure 1972-3

\begin{tabular}{|c|c|c|}
\hline & England & Scotland \\
\hline Central Government exnenditure. & $(\mathfrak{f} \mathrm{m})$ & $(£ 000)$ \\
\hline Central administration & $17\left(0 \cdot 8^{\prime \prime}{ }_{,}\right)$ & $1521\left(0.5^{\circ}\right)$ \\
\hline Hospitals & $1487(65.9 " 1)$. & $213847\left(70 \cdot 4{ }_{11}\right)$ \\
\hline Executive council services & $555\left(24 \cdot 6{ }^{\prime \prime}\right)$ & $66204(21 \cdot 8 \ldots)$ \\
\hline Miscellaneous & $51\left(2 \cdot 3^{\circ},\right)$ & $9526(3.1 \%)$ \\
\hline Total Government expenditure & $2110\left(93.5^{\circ \prime . .}\right)$ & $291098(95.8 \%)$ \\
\hline Local health authority expenditure & $147\left(6.5^{\prime \prime \prime)}\right)$ & $12702(4 \cdot 2 " \prime)$ \\
\hline Total Health Service expenditure & $2257\left(1000_{0}^{\prime}\right)$ & $303800(100 \%)$ \\
\hline
\end{tabular}

Source: Health and Personal Social Services Statistics for England 1974; Scottish Health Statistics 1973.

\section{Where the money goes}

One could argue at length about even this small selection of statistics. It would be tempting, but I think misleading (since it is notoriously difficult to establish the proper attribution of administrative overheads), to claim that the table shows Scottish central administration to be more economical than its English counterpart; and the figures for executive council services need much more analysis to make sense. What does, however, reflect a genuine difference is the higher proportion of expenditure devoted in Scotland to the hospital service: a difference of $4.5^{\circ}$, representing an additional expenditure of the order of $f 13 \mathrm{~m}$. This difference has its counterpart in the relatively much lower level of local health authority expenditure in Scotland. The figures seem to reflect a trend, going back many years, towards a greater concentration of resources on the hospital service in Scotland, based on a different assessment of the country's needs; and, looking back over the years, we can see that the proportion of expenditure devoted to the hospital service has shown a steadily rising trend, no doubt illustrating the limitations on manoeuvre imposed by an established service with its own builtin momentum. Perhaps we can see a reaction against this trend and an attempt to promote the development of the community services in the attention devoted in more recent years to the health centre programme and the building up of the local authority social work services. However this may be, it is clear that the Scottish Health Service has been able to develop its own distinctive patterns, while still providing broadly the same standard of services to patients as in other parts of the United Kingdom.

Within the overall programme the detailed decisions on priority-between one hospital project and another, between one health centre and another, or between a hospital project and a health centre-are taken in Scotland. In this field we can expect the new Scottish Health Service Planning Council to play an increasingly important part.

It is not the function of this background paper to speculate on the effect which devolution may have on these arrangements. Under the proposals in the Government's White Paper, ${ }^{3}$ the Health Service will become the responsibility of the Scottish Assembly and its executive and will be financed, along with other devolved services, from the block grant which will be settled each year after discussion between the UK Government and the Scottish administration. Probably the block grant will be built up by a process similar to the present machinery for preparing departmental estimates, giving weight to existing commitments and allowing a relatively small margin for development. The Scottish Assembly will have power to use the block grant as it thinks best. It will be able, for example, to switch resources from one field of expenditure to another; but as a matter of practical politics, given the acquired momentum of existing services, the scope for transfers of this kind will inevitably be limited. It will remain the function of the Scottish Home and Health Department-supported no doubt by the Scottish Health Service Planning Council-to defend and promote the interests of the Health Service against possible competing claims on resources which will necessarily always be limited: a task in which it has not, I think, been entirely unsuccessful in the past.

\section{References \\ ${ }^{1}$ Control of Public Expenditure, Cmnd 1432. London, HMSO, 1961. \\ 2 Public Expenditure to 1979-80, Cmnd 6393. London, HMSO, 1976. \\ 3 Our Changing Democracy: Devolution to Scotland and Wales, Cmnd 6348. London, HMSO, 1975.}

Edinburgh, Scotland

JAMES HOGARTH, CB, formerly under secretary, Scottish Home and Health Department

\section{View of BMA in Scotland}

\section{A W WRIGHT}

The White Paper, Our Changing Democracy, was published in November 1975 and has been considered by the committees which represent the profession in Scotland. The Scottish Council collated the views and sent them to the Minister for Health in Scotland. Subsequently the Chairman of the Scottish Council and the chairmen of the main committees met him to discuss the Association's views.

The BMA in Scotland is opposed to devolution and this view is shared to a large extent by the Scottish royal colleges. However, the document produced by the Scottish National Party's Health Policy Committee shows that some doctors in Scotland favour devolution.

\section{Consultants and the universities}

We believe that the NHS in Scotland provides a service which, in relation to standards elsewhere in the United Kingdom, is very good. There are four medical schools and three royal colleges in Scotland and, unlike England and Wales, consultants in Scotland work closely with the universities. Most of them are members of the clinical teaching staff and they are also connected, to a varying degree, to the royal colleges. This close relationship with the medical schools and the universities is of great benefit to the Health Service in Scotland. The White Paper does not envisage that the medical schools will be devolved from the University Grants Committee, but the universities, with their senior lecturers and honorary consultants, are very much concerned with Service commitments in Scotland. The general view of many consultants in the university field is that Scottish 
universities should remain under the administration of the University Grants Committee on a United Kingdom basis.

Scotland's medical schools provide many more graduates than the country requires. But Scotland flourishes as a centre of medical education and any contraction in the educational field would be detrimental. The BMA is concerned that a contraction related to the needs of the population might be attractive on economic grounds to a Scottish Assembly.

\section{Relationship with Government}

The relationship with the Scottish Home and Health Department is good and, because of personal relationships, has been most productive for the Health Service. We would like this to continue.

The White Paper refers to a block grant to Scotland's devolved assembly. The proportion of this to be devoted to the Health Service is to be decided by an elected health committee from the elected Assembly. Most doctors are concerned about the calibre of the Assembly's membership and of the health committee. The White Paper is unclear about how the health committee would be informed on health matters and how it could influence the already complex advisory structure of the Health Service. A health committee from the politically elected members of the Assembly would increase political influence in the Service at a time when many people think that the influence of political parties on health services should be diminished.

The White Paper refers to the regulation of the profession and suggests that while the present arrangement for the control of matters of undergraduate education and standards should for the time being remain with the General Medical Council these functions could be undertaken by a Scottish body at a future date. The BMA wants the GMC to continue to exercise its present function on a UK basis.

\section{Terms and conditions}

With regard to terms and conditions of service we think that in the Health Service these should also remain on a UK basis. Any change in this arrangement might mean a movement of doctors from one country to another to the detriment of the Health Service. The White Paper indicates that the Civil Service should remain on a UK basis and there is no reason why the medical profession should not be treated in the same way.

Bangour General Hospital, Broxburn, West Lothian

A W WRIGHT, MD, FRCP, general physician

\section{Discussion}

DR STEPHEN LOCK (1): I'm still not sure from your working paper, Mr Hogarth, how far Scotland is subject to control from Whitehall-for instance, in establishing basic standards.

MR JAMES HOGARTH (2): The service to the patient is very much the same throughout the United Kingdom, perhaps provided in slightly different ways. These standards must have been arrived at by discussions between the health ministers, but once they were accepted, there was plenty of room for variation in the way the service was provided. Some of these were statutory differences, and some have developed as a matter of practice. In Scotland, for example, there are two alternative statutory methods of providing health centres-by the Secretary of State or through the local authorities. In England it's the latters' responsibility, whereas in Scotland we found in practice that it usually worked best if the Secretary of State provided the centres.

DR GORDON MACPHERSON (3): The emphasis on hospital services mentioned in your working paper came as quite a surprise. With the shift towards primary care that's now going on in England, what would happen if Scotland were to resist this trend? How much pressure would Whitehall put on Scotland to change its attitude?

MR HOGARTH: Not at all in this type of priority. If Scotland were foolish enough not to want to expand primary care, that would be its affair-but it's unlikely that it would happen. The decisions on hospital spending were taken many years ago; the community services, which have recently been expanding rapidly, received a particular impetus from the social work legislation.

DR A W WRIGHT (4): At present our hospital services are grossly misused because of the absence of full primary care.

DR LOCK: It could be argued that Whitehall should have insisted on better primary care services in Scotland rather earlier on-perhaps this deficiency is a disadvantage of the devolution Scotland already has.

DR WRIGHT: At one time hospital authorities would have resisted any switch, because of the legacy of poor buildings and services they inherited from pre-NHS days. But I think they've now changed their attitude and would see the merit of diverting resources to primary care.
DR W KEITH DAVIDSON (5): Yes; some aspects of primary care have lagged behind England (particularly community services), but the standards of the hospital service before the NHS were abysmal.

DR T F DAVIES (6): Is the fabric of Scottish hospitals any worse than that of those in some of the deprived areas in England?

MR DAVID HAMILTON (7): Yes, I think so, and I've worked in various hospitals in England as well.

DR WRIGHT: I doubt if there's all that much difference; the point is that it's really scandalous that anywhere in Britain in 1976 hospital patients should be looked after in what an architect friend of mine has called "agricultural type buildings"- the EMS hutted hospitals built in 1940 to last 10 years. Their replacement was approved over 20 years ago, but both Dr Wood and I are still having to work in buildings of this type.

\section{Teaching hospital links}

DR R A wOoD (8): Another reason for Scotland's greater expenditure on hospitals is the emphasis on teaching hospitals and the close links between them and all the district hospitals.

MR HAMILTON: Any simple comparison in expenditure between the two countries means very little: we've particular problems in Scotland which invalidate this-poverty, a burden of ill health, scattered rural communities, and large numbers of teaching beds.

MR RUDOLF KLEIN (9): Scotland doesn't spend more than England just on health: expenditure on other services shows a similar pattern. The 1974-5 figures ${ }^{1}$ show that expenditure on housing in Scotland was $£ 92$, as against $£ 74$ for England and $£ 65$ for Wales. So it isn't that the NHS in Scotland is compensating for underspending on other services.

DR wooD: Again, you can't compare figures here, because a far greater proportion of Scottish housing is provided by the local authorities.

MR KLEIN: But these differences in expenditure must reflect local decisions on priorities, rather than on decisions taken in Whitehall. 